\title{
Central Nerve System Malignant Tumors
}

\author{
Sepehr Rahmani ${ }^{1}$, Ling Shing Wong ${ }^{2}$ \\ ${ }^{I}$ (Faculty of Science, Technology, Engineering and Mathematics/ INTI International University, Malaysia) \\ ${ }^{2}$ (Faculty of Science, Technology, Engineering and Mathematics/ INTI International University, Malaysia)
}

\begin{abstract}
Tumors are classifying in two different types- non-cancerous (benign) or cancerous (malignant), which the malignant tumors are generally classified into meningiomas and gliomas tumors that varies in types. Some tumor occurrence are depend on the area that cells arise such as oligodendrogliomas, ependymomas and astrocytomas occur mostly from the meninges, which is outer part of brain and spinal cord. Even though they arise outside of the brain meningiomas do not be considered as brain tumor, because $85 \%$ of meningiomas are benign and can cure by surgery. Beside the three mentioned tumors meningiomas astrocytomas and glioblastomas mostly seen in adults, number of uncommon brain tumors containing medulloblastoma that arise from the cerebellum of primitive stem cells and most seen in children.
\end{abstract}

Keywords: Benign, Gliomas, Glioblastoma multiform, Meningiomas, Astrocytomas,

\section{Introduction}

Brain is center of nervous system in vertebrates. Brain located in skull which on animal's head and close to primary neurological body parts and organs which have senses like taste, vision, smell, hearing and balance. Among the vertebrate body, brain is the most complicated and complex organ. In normal human, the largest part of brain (Cerebral Cortex) is likely surrounds 15-33 billion neurons [1]. These neurons interlinked to other neurons over synapses.

Brain is the central control of body and organs. Brain can control different parts of body by hormones (secretion of chemicals) and generating patterns activity of muscles. This central control allows fast and synchronized reactions to changes in the environment. Some primary kinds of receptiveness such as reactions can be mediated by peripheral ganglia and spinal cord. But innovative fills with meaning control of actions based on complicated neurological feedback requires the information-integrating abilities of a central brain. Human brain has different three parts which called hindbrain, midbrain and set of common structure of vertebrate brain contain pons, optic rectum, medulla oblongata, thalamus, cerebellum, olfactory bulb, hypothalamus and basal ganglia.

The weight of brain in adult human is about $1.5 \mathrm{~kg}$ [2] and the volume of brain in adults are around 1130 cubic centimeters and 1260 cubic centimeters correspondingly, with a considerable variation among individuals [3]. Relatively, man's brain is heavier on average of 100 grams [4]compare to a woman's brain at same physical conditions but difference in brain weight does not associate in any way with actions of intellectual performance or IQ [5]. In largest part of the brain, cerebral hemispheres which located on top of other brain structure are covered with an elaborate topography with cortical layer [6]. Brainstem lies below the cerebrum. Cerebellum with horizontally structure and wrinkled surface can be easily identified as other brain areas is located behind the brainstem, at the back area of the brain and lower than cerebrum. A live brain have steadiness like soft tofu or gelatin and it is very soft. The color of live cortex also is pinkish beige and interior slightly white.

Group of diseases that relate to tolerant of cell growth are considered as cancer. Cancer cells grow and divide nonstop and invade different parts of body. They also can spread through bloodstream and lymphatic system. All tumors do not consider as cancerous, benign tumors do not attach tissues in neighboring and do not spread to the different parts of body. Nowadays there are more than 200 different known types of cancer which can cause serious problem on humans [7].

There are multiple reasons for cancer, such as exposure to UV radiation, diet, smoking including tobacco, certain infections, environmental factors like pollutants and [8]. There are factors that can damage the genes or cause mutation by combining to the genetic faults within cells that contributes to the occurrence of cancers as well [9]. Cancer can be identified in a several ways, like screening tests, and medical imaging. The usual treatments for cancers are surgery, chemotherapy, and radiation therapy. The chance of recovery depends to the type of cancer, the location of tumor, and how early is the disease being diagnosed. Whereas cancer can affect human in different ages like kids, teenagers and adult people but some types of cancers are common in children, while a few others are common in adults [10].

In the United States and Canada, One of the most common cancers in childhood is brain cancer $[11,12]$ . In United State of America, one of the most common tumor in children is solid tumor rose from 2.3 cases per 
100k of population in 1975 to 3.0 cases per 100k in 1998 [11]. In Canada the rates were similar to United State [12]. There is different concern about factors that increase the risk of cancer. One of them is environmental factors which were increased by years. Another idea is improvements in detecting tumors and classifying brain tumors (MRI) have linked to increase in time, even though this it is contentious [13] The causes of brain cancer in children are basically unknown, But there are several fundamental causes which can due to brain cancer in children that linked to genetic and chromosomal conditions like Li-Fraumeni syndrome, Down syndrome and tuberous sclerosis that are small percentages of all cases [14]. Another factor that also connected to children's brain cancer is exposure of therapeutic irradiation [15]

\section{Brain cancer}

Tumors can be two different types non-cancerous (benign) or cancerous (malignant) but cancers are surely malignant. General classification of primary brain malignant cancers include two main types: malignant meningiomas and gliomas tumors that varies in types. Tumors name depends to the area that cells arise such as oligodendrogliomas, ependymomas and astrocytomas occur from the meninges, which is outer part of brain and spinal cord. Even though they arise outside of the brain but cannot consider meningiomas as brain tumor, the $85 \%$ of meningiomas are benign and can be diagnose or cured by surgery. Beside the three mentioned types, number of uncommon brain tumors containing medulloblastoma that arise from the cerebellum of primitive stem cells and most seen in children. As well primary and secondary malignant tumors can arise in the brain. Actually the secondary tumors arise from different parts of body then extended to the brain (metastasis) [16]

. Over $20 \%$ of all cancers diagnosed among 0-14 years old [17]. 75\% of children's brain tumors is astrocytomas and the rest is medulloblastoma[16]. Generally after 10 years of age the chance of brain cancer increases with age (25-75). In adult people the common brain cancers are astrocytes tumor which is a multiform. Men have a higher chance compared to women to get this type of brain cancer, in broad brain and nervous system cancers can occur in white people which has higher incidence compare to black men and women. But meningiomas is common in black men and women compare to whites [18].

\section{Types of brain cancers and grades classification}

The tumors in human can be in two types malignant and benign that can be primary or secondary, which can grow different parts of body and spread in body. The tumor which started to grow in brain as divergent to a metastasis tumor (which spreads to the brain from different parts of body) is called primary tumor [19]. The chance of cancer cells spreading from other parts to brain compare to primary tumors 4 is to 1 [20]

. Some tumors have symptom but some doesn't have, but there are some methods which can prove the existence of tumors in body for instance imaging scan and autopsy. The tumors which are very common between people are gliomas(50.4\%), meningiomas(20.8\%), Pituitary adenomas(15\%) and nerve sheath tumors(8\%)[21]. There are numerous types of brain cancer (tumors), each with specific classification by grade. The tumor's grades help to find the best treatment method because different tumors with different grades have different structure and aggressive level. The most benign tumors are classified as grade I that appear under microscope. Grade II tumors are cells that can become to malignant more easily which can destroy and invade the healthy neighboring tissue and cells. The malignant tumors that are graded as III and IV, does not define prognosis because the location of tumor can influence the treatment and removing [22].

\section{Gliomas}

Gliomas is a caner that starts to grow in spine or brain, brain is the common site of gliomas. Its arise from glial cells that's why it's called gliomas.[23]. 30\% of central nervous system and brain tumors are built up by gliamas and most of the malignant tumors in brain [24], gliomas also consider as tumors that demonstrate immunohistochemical, ultra structural and histological of indicate glial variation. The gliomas is classified by their cellular features by the world organization classifies. The gliomas types are Ependymal or oligodendrocytes and Astrocytes, gliomas malignancy grades are from I to IV [25]. The most common class of aggressive forms of cancers and one of the malignant primary brain tumors are GBM (Glioblastoma multiform) or Astrocytoma (IV) which the survival after diagnosis is usually 12 months for astrocytomas (IV) and 6 months for glioblastoma multiform [25][26]. Furthermore the GBM is highly resistance to chemotherapy and radiotherapy. These malignant features of tumors maybe related to the different types of mutation that occurs frequently in these tumors [26][27]. The current treatment strategies for GBM are only surgeries resection and pivotal radiotherapy. As GBM is resistance to chemotherapy, different chemotherapeutic agents are tested such as alkylating agents ( temozolomide) and nitrosoureas (carmustine) but no improvement in patients has been succeed [28]. 


\subsection{Types of high grade Glioma}

There are three types of high-grade tumors which is consider as glioma according to their cells types that is closely look like. ependymomas arise and develop from cells called ependymal which can be high grade and low grade and they line the cavities of brain. The ependymomas classified in 2007 by world health organization to three grades. Grade I contains myxopapillary ependymomas and subependymoma. Grade II consistent to ependymoma and grade III including anaplastic ependymoma and normally clear cell and tanycytic ependymomas, cellular and papillary belongs to one or more grades usually grade I and grade II [29].

Generally the ependymomas are well-defined, which can grow and arise to the meningeal carcinomatosis. Low grade ependymomas consist of monomorphic cells to elliptical the nuclei which contains discrete chromatin. In high grade neoplasms the cells are polymorphic, hyper chromatic and erratically shaped [30]. Appreciation of ependymomas contains perivascular rosettes, an anuclear perivascular zone contains of ependymal cell procedures outward of blood vessels. They characterized with GFAP and vimentine antibodies. When the density of tumor cell is low these structures are challenging to classify. Irregular distribution of nuclei which has fibrillary background recommend histological verdict of ependymoma. Perivascular are hard to evaluate in highly cellular regions. Another one is ependymal rosettes which is extremely representative of ependymoma. It is rarely observe, within rosettes. Generally this types of tumor cells essence around the lumen. These structures need to differentiated from the normal one to ependymal coating of ventricles when they are forming a canal and larger. In other side when they are small central contains of accumulation of microvilli which responds with antibodies against EMA, There is limited for ependymal tumors to intense Intracytoplasmic eosinophilia dense. Ependymal tumors in perivascular area are marked with GFAP, if GFAP was absence the strategy for diagnosis should change and take another treatment. Furthermore the ependymal tumors are very constructive for NCAM [31].

Subependymomas are tumor cells that grow slow, through a slender peduncle and broad base and devotee to the wall of the ventricles. Most common location for subependymomas (low-grade lesions) is fourth ventricles. The spinal cord and third ventricles are not very common grow locations for subependymomas. Generally subependymomas is in adult patients when they are symptomatic with clinical exhibitions. This tumor's background is cystic changes and very fibrillar, nuclear sometimes scant and change to form group, this hangs in vessels may be due to intravascular thrombosis resulting in necrosis and another tumor which called secondary intratumoural haemorrhage [32].

Myxopapillary ependymomas are slow growing tumors. The usually grow in filum or conus terminal and its common in all group of ages but most in young adults. They normally are shown by back pain. They can grow and rise to CSF distribution which very common in children than in adults like other ependymomas [32]. The histological feature of myxopapillary ependymomas is ring of mucin lined by cubical ependymal cells that surrounded pseudo papillary structures that containing of a centrally located vessel, which is the juxtaposition. The myxopapillary ependymomas is contains balloons when they have more solid feature that resemble to eosinophilic structures.

Two other types of ependymomas are cellular and papillary ependymomas that as consequence the cellular one is highly cellular scratches and presenting a monotonous feature and Lacking of anaplastic feature. The papillary one represented by papillary structure in central vascular and surrounded by cylindrical cells. One variant observed tumors in the supra tentorial compartment which less common in posterior fossa and spinal cord is called clear cell ependymomas. Teenagers have higher chance to affect to this tumor compare to other group ages. They cells arrangement is back to back with cytoplasm this similarity to oligodendrogliomas that shows chicken-wire structures spreads to blood vessels and GFAP needed to mark them. They grade III when the endothelial cell area explosion and mitosis happens in this tumor nonstop. They will be grade II in absence of lesions [33].

Another type of ependymomas tumor that occurs in spinal cord rather than brain is called tanycytic ependymomas. Generally tumor cells arranged and elongated is important in treatment and diagnosis strategies, For instance in absence of a rich reticulin network and presence of perivascular rosettes the nuclei will labeled with antibody which against oligo2 make easy curing of ependymoma. Normally the monomorphous Angiocentric Glioma attacks the cortical abrasion, also its possible to rich to the white matter. This type, first described as epilepsy in patients usually with the long term. monomorphous angiocentric glioma reveal EVA positive intra cytoplasmic dots, it is differ from ependymomas because of the accumulating of tumor cells in the subpial area, and also they are highly infiltrative aspect [34].

One type of infrequent well circumscribed ependymomas tumors is astroblastoma which grows and arise in the cerebral hemisphere. It's presenting bubbly aspect in the cystic and solid areas. It doesn't contain perivascular fibrosis and ependymal rosettes that make easy to differentiate them from ependymal. In astroblastoma can see EMA positive staining which is another feature of astroblastoma [35]. Papillary glioneuronal tumor is completely supra tentorial distinction ornamental lesion that possibly is cystic. It contains 
a pseudo-papillary GFAP positive network surround the centered on hyalinized vessels and core like structures and intermediate zones filled by synaptophysin positive neurocytic cells [36]. Oligodendroglioma is different

kinds of ependymomas tumors which may have arisen from clear cell ependymoma, for example like GFAP positive and EMA staining with latter diagnosis. It is not grow in children because the deletion of $1 \mathrm{p} / 19 \mathrm{q}$ normally doesn't happen in children [36].

Central neurocytoma another type of malignant tumors that referred to ependymoma of the foreman induce different diagnosis with clear cell ependymoma. This type of tumor occur and present in the third ventricular system and it's possible to evoke the intracranial hypertension. The nuclei area will change with fibrillary that are not positively stained for GFAP but stained for synaptophysin [37].

The last type of ependymomas tumors us pilocytic astrocytoma which is hard to cure and has challenging diagnosis, this diagnosis problem arise when this tumor located in the spinal cord. Nuclear immunopositive staining for olig2 favors an astrocytic neoplasm when areas of Rosenthal fibers, granular bodies and loose micro cystic textures be absent. Furthermore two types of tumors are recognize in adult people which should differentiate from ependymomas. An ependymoma like tumor in the pineal region and more lack of GFAP marking and stain for cytokeratins is called papillary tumor that has a very difficult diagnosis in adult people. The paraganglioma needs different diagnosis as ependymoma when it is located in the down area of spinal cord, the PS100 antibody will help to highlight the lobules of chief cells that are synaptophysin and chromogranin positive [38].

Astrocytomas tumors are arisen from glial cells, glial cells are structured in spinal cord and brain and another function as feeding nerve cells and important role in memory and playing in people. This tumor doesn't have any specific place to grow in other hand they can occur at any part of the brain, they can grow slowly and rapidly in invade surrounding brain tissue. The astrocytomas tumors classified as malignant tumors with grade I to IV. The fourth grade means doesn't look like brain tissue and grow fast. The I grade can happens in children and teenagers they are less invasive compare to grade III and IV. The grade III called anaplastic astrocytomas and last one which has hard diagnosis process and high mortality rate called glioblastoma multiforme (GBM), in other word astrocytomas grade IV [39].

\section{Meningiomas}

Meningiomas is a type of brain cancers which can happen from all Dural constructions, spinal and cranial are outside of these structures and meningiomas arise from arachnoid cells[40]. The human skull is a place that has different neural system and structure as well as brain contributing nearby veins and arteries. Meningiomas, can grow on different places such as on or within the skull which can be very inspiring for neurosurgery. In surgeries usually is not possible to remove all tumor cells without any damage [41][42] and normally these surgeries in petroclival meningiomas area are very dangerous. But microsurgical technique allows control of recurrent tumors and residual as well as removing the meningiomas.

One of the brain cancer types that consider as most primary intracranial neoplasm is meningiomas, that expressive

$14 \%-19 \%$ of all intracranial tumors. Also, estimated occurrence is around 0.001 with attuned sex and an age, incidence rate of 0.000036 and 8.4 in a year. Meningiomas tumors are classified by grades I, II and III. The aka benign meningioma (grade I) is a majority of meningiomas around $80 \%-90 \%$. About $4.7 \%$ up to $20 \%$ of meningiomas are consider as aka atypical (grade II) which has $d$ to $2.8 \%$ of all meningiomas[43]

. Meningiomas tumors are arise in different ages even newborns can affect to this tumor. Occurrence peaks distinctly in the fourth and sixth decades [44]. Distribution of sex shows women pre-dominance in different ages with a significant peak of about 2 to 1 in the 30s and 40s[45].

In general one out of three of meningiomas are consider as skull-base meningioma, the tumors normally arise from three different parts of brain, for instance less than 10 percent of meningiomas tumors are arise arachnoids of the olfactory groove, 12.8 percent tuberculum sellae, 17 percent sphenoid ridge and less than 4 percent from foramen magnum. The least meningiomas tumors arise can arise different parts of brain such as medial $30.1 \%$, alar or outer $6.9 \%$, clinoidal, temporal or pterional $16 \%$ of the sphenoid ridge[46][47]. 


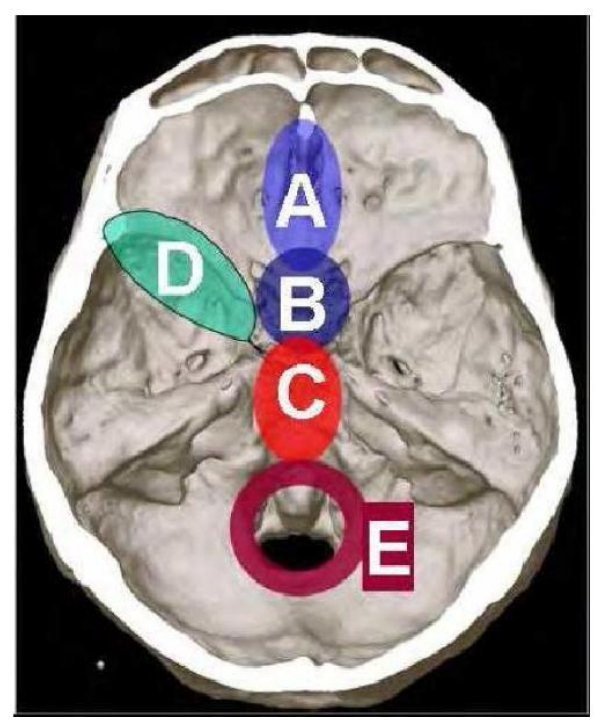

Fig. 1. Computed tomography of the skull base with marked areas of meningioma occurrence, A: olfactory groove, B: para- , suprasellar, C: petro-clival, D: sphenoid wing, E: foramen magnum.

In general brain cancers have nonspecific symptoms before diagnosis and treatment like headache for years. Seizures also have seen in skull base meningiomas and disobediently to tumors of the bulge. Seizures most happen in sphenoid wing cases among skull base meningiomas[48].

Meningiomas tumors also can grow in frontal skull base, most in the olfactory groove and before diagnosed the size can reach to grotesque (fig2), may occur very slowly and doesn't change the quality of patient's life immediately due to that hypo or anosmia. Other neurological symptoms will appear in patient when the tumor spread along midline and grow enough to get to the tuberculum sellae. The frontal base lobe can psychotic and induce incontinence after affecting to the cancer for instance can mention to some of them like psycho-motor disabilities, mental weakening and personality changes. Visual disorder can happen due to reduction of vision and blindness or bitemporal hemianopsia. Moreover there are some other reasons for inducing endocrinological disturbance such as compression of pituitary stalk [54]. hypothalamus and

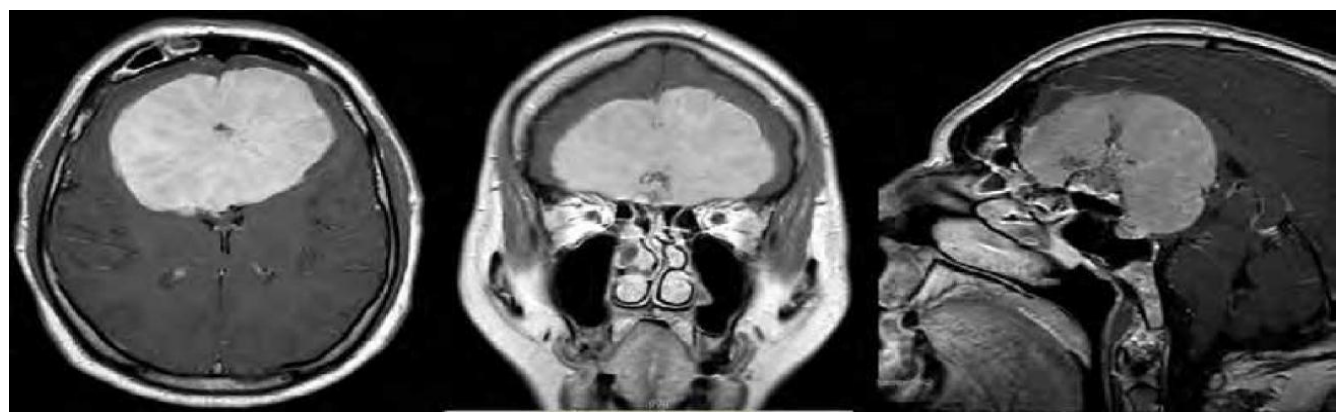

Fig. 2. T1-weighted triplanar magnetic resonance tomography after application of gadolinium, revealing a huge

tuberculum sellae meningioma with homogenous contrast enhancement

Meningiomas tumors can arise and grow in sphenoid ridge which causes different neurological symptoms. When it spread to the middle skull groove and the optic nerves affected by cancer cells can persuade visual disorders. Due to compression of eye movement nerves and loss of ultimately and sensibility even principal to a keratitis, diplopia can happen in this patients. When meningiomas invades the Bone sphenoid wing it causes hyperostosis [49].

Cranial nerves may get affected due to extensions of tumors going through the cilvus. Mono or hemiparesis, paresthesia besides occlusive hydrocephalus can occur according to the location and the mass of tumor (fig3). 


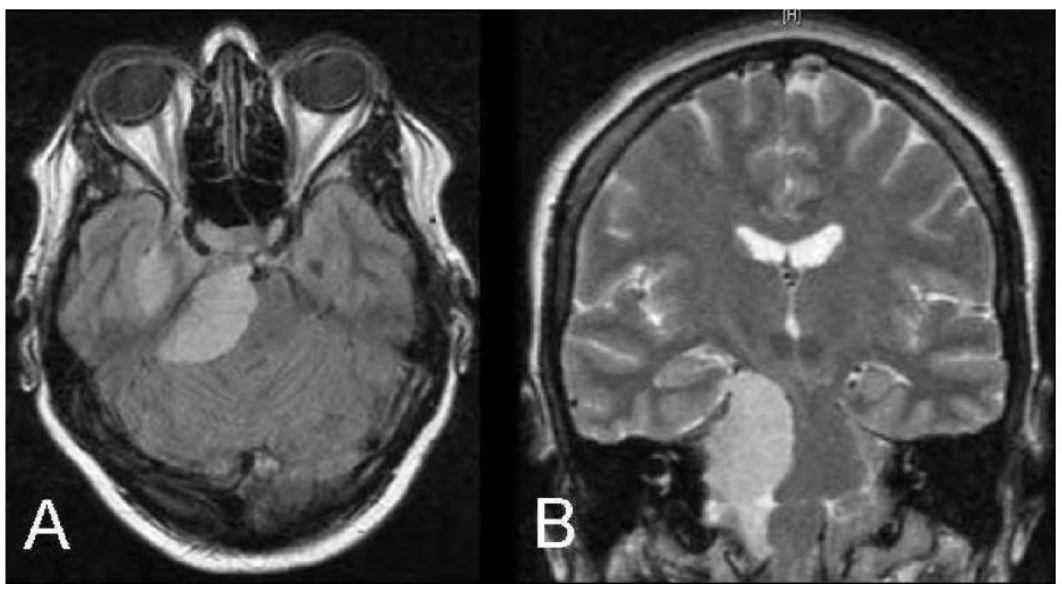

Fig. 3. Magnetic resonance tomography (A: T1 weighted, B: T2 weighted, both after application of gadolinium), showing a right sided petroclival meningioma.

Meningiomas tumors can expand and grow within the ventral, foramen magnum, dorsal or lateral it is possible to affect the lover eye movement nerves besides brain function. Furthermore the occlusive hydrocephalus may occur because of disorder of the aqueduct. In addition the tumors (meningioma within the posterior fossa) are arise from the tentorium may wrap or attack the cerebral sinus and arteries. There is possibility that meningiomas tumors (within posterior fossa) infuriate dysmetry, cerebellar function, inducing ataxia, tremble and dizziness [48].

\section{Pituitary adenomas}

The tumors that arise in sella region are vary and numerous. They include tumors such as craniopharyngiomas, pituitary adenomas, primary and secondary Carcinomas and meningiomas, etc. the pituitary adenomas generally is benign tumors but some types of pituitary adenomas can invade the neighboring cells and tissue and the growing rate also is fast, some benign types that are not able to invade the neighboring cells are slow-grow, restricted to the sella turcica, one of the characteristic feature of the pituitary adenomas are able to spread to others parts.

Like other brain cancers pituitary adenomas also has some symptoms which can say most of them are same as actrocytomas, gliomas and meningiomas tumors like headache, increased intracranial pressure, optical disturbances and damage of numerous cranial nerves. Many of them due to main changes in endocrine homeostasis and increase some hormones in blood.

The pituitary adenomas contains gigantism, the amenorrhea-galactorrhea syndrome, hyperthyroidism, Cushing's disease and acromegaly. This tumor is very common in the sella region, Base on the surgical experiences approximately $10 \%$ to $15 \%$ and according to the sections examined they renowned in $3 \%$ to $24 \%$ of unselected autopsies of intracranial tumors are represent by pituitary adenoman in sella region. Pituitary adenomas frequency is not different between women and men if one includes every type.

Though the diagnosis of pituitary adenomas in prepubertal ages is very rare and it can appear and form in all age groups from children to adult. There are some parameters for classifying the pituitary adenomas such as biochemical methods measuring blood hormone's concentrations using radioimmunoassay. In the other hand classifying different types of pituitary adenomas by analyzing separately, because they have significant differences for instance the corticotroph adenomas occur in women rather than men, gonadotroph and oncoytomas adenomas is more common in men with age over 40 than women, prolactin secreting adenomas is generally common in null cell adenomas and surgical material in young women.

There is other method in classifying the pituitary adenomas which is morphologic characteristic of the stress different markers of the disease but nowadays there is modern pathologic classification is based on cultured morphologic techniques like molecular methods and morphometric analysis (in situ hybridization), immunocytochemistry, immunoelectron microscopy and transmission electron microscopy. Some types of pituitary adenomas with their prevalence percentagea are somatotroph adenoma (13\%), lactotroph adenoma (29\%), corticotroph adenoma (10\%), thyrotroph adenoma (1\%), gonadotroph adenoma including (47\%) and null cell adenoma and $\mathrm{o}=$ Oncocytomas.

In conclusion pituitary adenomas is classified by size, giant adenomas $(>40 \mathrm{~mm})$, macro adenomas $(>10 \mathrm{~mm})$ and micro adenomas $(<10 \mathrm{~mm})$ [50], staining affinities of the cell cytoplasm, hormone production and contents, endocrine activity, histologic characteristics, cytogenesis, cellular composition, growth pattern, granularity of the cell cytoplasm, ultrastructural features and by they function they divide to two types with different subtypes which is depends to the grow hormone and prolactin and etc, NSPA (non-secreting 
pituitaryAdenomas) and SPA (secreting pituitary adenomas).

The symptoms of pituitary adenomas is caused by different reason such as producing abnormal amount of hormones or abnormal secretion of hormones deficiency or hyper secretion like Cushing's disease and acromegaly Another reason of symptoms can be by the type of tumor, tumor dimension and structures [51]. For the last reason can mention to that some patients will have other pathology such as blindness and consciousness, intracranial hypertension which caused by changing of tumor volume that mean changing tumor from secondary to intratumoral hemorrhage and infarction [51][52]. Although there are so many diagnosis strategies but surgery still is main method for removing pituitary adenomas tumors and curing patients [53].

\section{Nerve sheath tumors}

Other type of brain tumors which is a rare soft tissue of sarcoma of ectomesenchymal origin, called MPNST (Malignant peripheral nerve sheath tumor) [55,56]. WHO devised these malignant peripheral nerve sheath tumor confusing terminology and replacing previous heterogeneous, like malignant neurilemmoma, and neurofibrosarcoma and malignant schwannoma for neurogenic origin tumors $[57,58]$. Diagnosis of this tumor is difficult because of the histopathological similarities between their cells and spindle cells such as leiomyosarcoma, fibro sarcoma and monophasic [59]. Minor and major peripheral nerve branches and sheath peripheral nerve fibers generally are the place this tumor arises [60]. MPNST tumors are arise in adults which $5 \%$ to $42 \%$ of them are multiple neurofibromatosis Type-I [61-64]. For diagnosis of this type of tumor different strategies and treatments is use such as histopathological, immunohistochemical and combination of gross. Another wondering feature about these tumors with same histology is growing and change to secondary tumors and being multifocality [59],even though these tumors are aggressive in nature but surgery still is main treatment $[59,64,65]$.

Malignant peripheral nerve sheath tumor is not a very common tumor that's why the incidence is 1 per 100000 in population and its constituents is between 3 to $10 \%$ of all soft tissue sarcomas [55, 56]. In most examples the tumors demonstrate fascicles of spindle cells interlaced into herringbone shape with different degrees of necrosis and mitosis division. Nevertheless it is not possible always to display especially when it arise from a small peripheral branch from a nerve of origin. Most of them about $61 \%$ of this tumors don't demonstrate in cases of MPNST [64] and in

$45 \%-56 \%$ of cases the nerve origin could be identified only [66]. MPNST Still has different features for instance proliferation of tumor in small vessels in the walls of large vessels and the sub endothelial area of nepotistic cells herniation into vessel lumen. MPNST tumor occurs in male and female with the same frequency [60]. But still it is difficult to say gender could cause and increment in chance of getting MPNST base on referral prejudice. MPNST sometimes arises from unusual sites like pelvic retro peritoneum. Normally the preoperative electrophysiological examination is done because will confirm that diagnosis will affect the treatment plan or not [56]. Imaging is a routine way to decide the diagnosis and surgery plan [65]. One of the investigation ways is doing MRI because it can expose the origin of nerve and its relationship to adjacent structures [67]. But MRI has limitation for example we are using CECT (contrast enhanced computed tomography) for valuation of pulmonary metastasis where MRI cannot show that.

\section{Mortality and survival}

The mortality and survival rates of brain cancers in Western Europe, Australia and North America are around 3 to 5 per 100000 per year in women and 4 to 7 per 100000 persons per year in men [68, 69]. Incidence rates are similar to mortality rates in all areas. Survival of glioma cases are still very poor except pilocytic astrocytomas $[70,71]$. The survival cases with ages $-20,-15,-10$ and -5 are diagnosed with a supratecntorial low grade glioma. According to national cancer institute in 1973-2001 the cured cases with low grade glioma reported to epidemiology, surveillance and end results were $60 \%, 42 \%, 42.6 \%$ and $26 \%$ [72]. The chance of 5 years old glioma survival is less than $3 \%$

[70]. Older ages has significantly lesser and poorer rate of survival which can consider to the all ages group of glioma [70]. A research in wales and England with more than 30000 patients showed that some of them have longer survival that has socioeconomic status [73]. According to the same research in England and wales showed the diagnosis and survival of glioma increased from 1971-1990 [74]. Demonstrating of modern diagnosis and treatments still hasn't improved the outcome of cases with glioma tumors [75]. The rate of survival of children who were cured in Europe countries is different and vary but the probability of survival cases increased in 1982 compare to 1981. Chance of brain cancer can increase by some specific occupations such as diet, chemicals exposures, cell phones, smoking, therapeutic X-Irradiation, medical history (head injury, allergy and acute infections), electromagnetic fields and hereditary of tumor syndrome [76]. 


\section{Intracranial, Brain and other CNS tumors mortality statistics in the UK}

The recent mortality rate and statistical data for intracranial brain and other CNS are for 2011 in the UK. The presented charts are about mortality statistics of brain cancer and CNS and intracranial tumors in the UK. Brain and other parts of CNS have ICD codes which different codes present different brain and CNS cancers the presented tumors in this data are ICD-10C70-C72, C75. 1-c75.3, D32-D33, D35.2-D35.4, D42-D43 and D44.3-D44.5 these codes represent for primary tumors of the brain, spinal cord and other parts of CNS, meninges, pituitary gland, pineal gland all of these cancers are included malignant, benign unknown behavior tumors.

CNS, brain and other intracranial tumors are the $8^{\text {th }}$ most common cause of death in the UK at 2011 compare to other types of cancers. In 2011 4,975 deaths were from CNS, brain and other intracranial tumors in the UK. Table 1: Brain, Other CNS and Intracranial Tumors (C70-C72, C75.1-C75.3, D32-D33, D35.2-D35.4, D42-D43, and D44.3-D44.5), Number of Deaths, Crude and European Age-Standardized (AS) Mortality Rates per 100,000 Population, UK, 2011. According to the (Table 1), the deaths numbers from brain and other CNS and intracranial tumors in 2011, in the UK were 4.975. Men has 2.688 and women 2.287 which mean men with $54 \%$ and women $46 \%$ with the ratio of 12:10 [76-79]. The European AS rates do not have significant difference between constituent countries of the UK (Table 1) [76-79].

\begin{tabular}{|c|c|c|c|c|c|c|}
\hline & & England & Wales & Scotland & Norther & UK \\
\hline \multirow[t]{5}{*}{ Male } & Deaths & 2,229 & 157 & 219 & & \begin{tabular}{l|l}
83 & 2,688
\end{tabular} \\
\hline & Crude & 8.5 & 10.4 & 8.6 & 9.3 & 8.6 \\
\hline & ASRate & 7.1 & 7.9 & 7.1 & 8.6 & 7.2 \\
\hline & ASRate- & 6.8 & 6.7 & 6.2 & 6.8 & 6.9 \\
\hline & \begin{tabular}{|l} 
ASRate- \\
\end{tabular} & 7.4 & 9.2 & 8.1 & 10.5 & 7.5 \\
\hline \multirow[t]{5}{*}{ Female } & Deaths & 1,910 & 126 & 200 & & \begin{tabular}{l|l}
51 & 2,287
\end{tabular} \\
\hline & Crude & 7.1 & 8.1 & 7.4 & 5.5 & 7.1 \\
\hline & ASRate & 5.1 & 5.4 & 5.5 & 4.3 & 5.1 \\
\hline & ASRate- & 4.8 & 4.5 & 4.8 & 3.1 & 4.9 \\
\hline & ASRate- & 5.3 & 6.4 & 6.3 & 5.5 & 5.3 \\
\hline \multirow[t]{5}{*}{ Persons } & Deaths & 4,139 & 283 & 419 & 134 & 4,975 \\
\hline & Crude & 7.8 & 9.2 & & 7.4 & 7.9 \\
\hline & ASRate & 6 & 6.6 & 6.3 & 6.3 & 6.1 \\
\hline & ASRate- & 5.9 & 5.9 & 5.7 & 5.3 & 5.9 \\
\hline & ASRate- & 6.2 & 7.4 & 6.9 & 7.4 & 6.3 \\
\hline
\end{tabular}

Table, 1: Brain, Other CNS and Intracranial Tumours (C70-C72, C75.1-C75.3, D32-D33, D35.2-D35.4, D42D43,

and D44.3-D44.5), Number of Deaths, Crude and European Age-Standardised (AS) Mortality Rates per 100,000 Population, UK, 2011

\subsection{By age}

According to researchers in years and decades they show that the age is related to the CNS brain and other intracranial tumors mortality. The highest death rates is belongs to older women and men. But the brain, CNS and other intracranial tumors happen in all group of ages, however between 2009 and 2011 in the UK, men and women with the ages of 75 years and over have $34 \%$ of brain, other CNS and intracranial tumors death and $70 \%$ is belongs to the people with group age of 60 and over [76-79] (figure, 4.1).

The mortality rates in specific age are relatively stable in ages 25 to 29 years old, then has a steady arise until the 45 to 59 years old, but the rates has sharper arise with the group age of 85 years old and over. Death rates between male and female is close and is not really significant difference in age of 45 to 49 and 50 to 54. Mortality ration between male and female in age specific mortality is almost 17:10 [76-79]. 


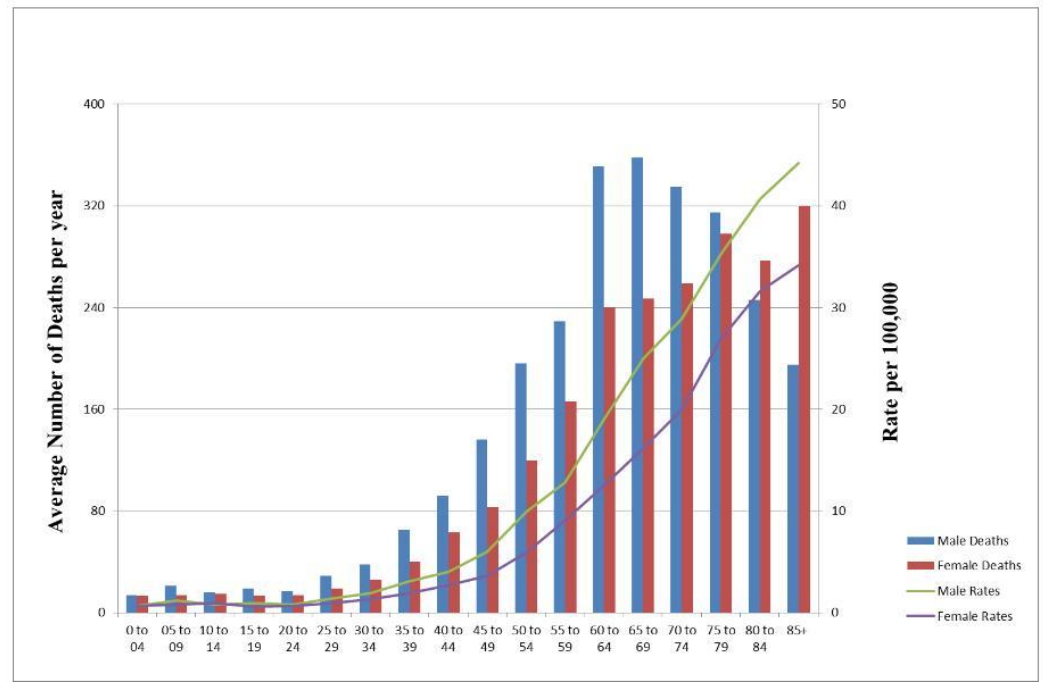

Figure, 4.1: Brain, other CNS and intracranial tumours (C70-C72, C75.1-C75.3, D32-D33, D35.2-D35.4, D42D43, and D44.3-D44.5), Average Number of Deaths per Year and Age-Specific Mortality Rates, UK, 2009-

$$
2011
$$

\subsection{Trends over time}

Since 1993 for the UK the Other CNS, brain and intracranial tumors mortality trends as shown in [ 7679] (fig, 4.2). Between 2000-2002 and 2009-2011, European age standardized mortality rates have decrease in males by $6 \%$ and stable rate in females.

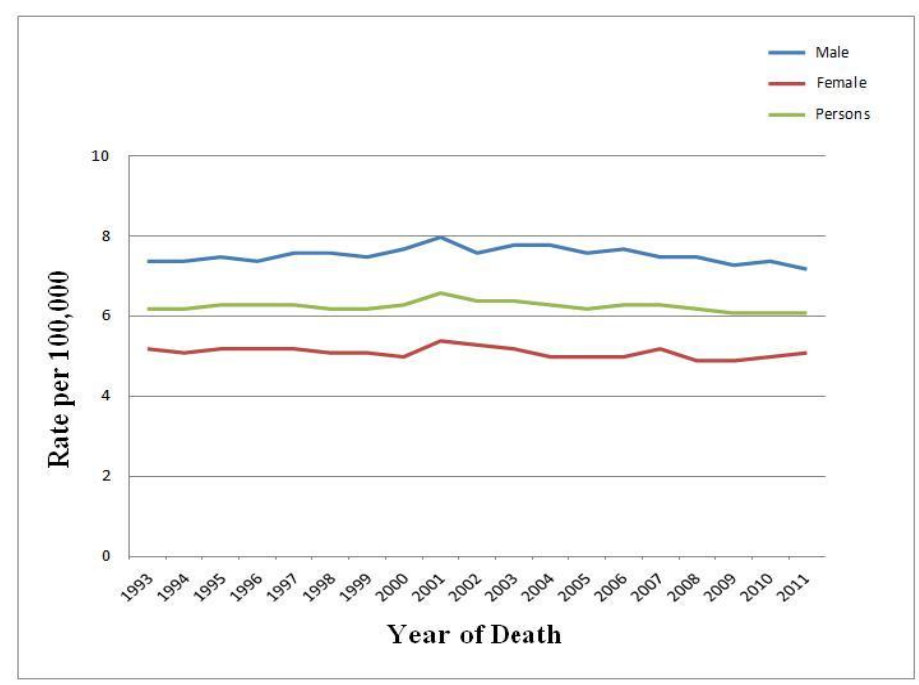

Figure, 4.2: Brain, Other CNS and Intracranial Tumours (C70-C72, C75.1-C75.3, D32-D33, D35.2-D35.4, D42-

D43, and D44.3-D44.5), European Age-Standardised Mortality Rates, UK, 1993-2011

Improvements in registration and different, new and more effective diagnostics are likely effect the mortality rates and decreased them in last decades. The effect is more obvious for benign and unknown or uncertain tumors than malignant tumors because for malignant tumors the records should be for long time which more reliable for malignant tumors, but overall the malignant brain, other CNS and intracranial tumors decreased in the UK since

1970s, though it had increased the late 1980s and early 1990s, according to (fig, 4.3) [76-79]. In males the age standardized mortality rates mortality rates in European increased by $24 \%$ between years 1971 to 1973 and 1990 to

1992. The male's pattern is same with women with the increasing rates of $21 \%$ between the years of 1971 to 1973 and 1998 to 1990. 


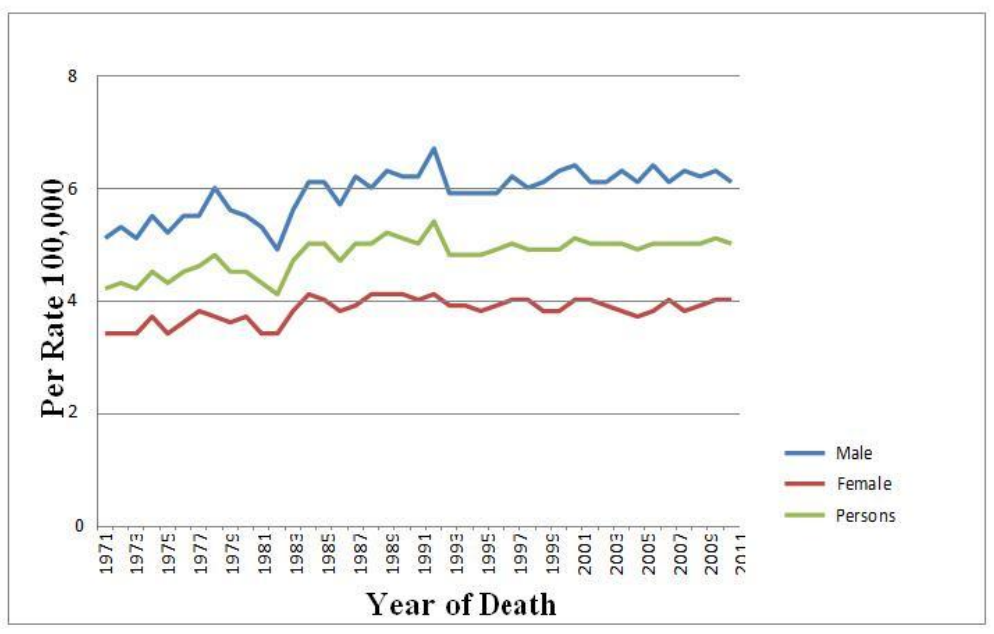

Figure, 4.3: Malignant Brain, Other CNS and Intracranial Tumours (C70-C72, C75.1-C75.3), European AgeStandardised Mortality Rates, UK, 1971-2011

Malignant other CNS, brain and intracranial tumors are decreased in rate overall in all group of ages under 60 in the

UK from early 1970s but increased in ages over 60 (fig, 4.4) [76-79]. The largest increase rate is in people with age of

80 and over and the largest decrease is belong to the people with age of 49 and under, with European age standardized mortality rates decreased between years of 1971 to 1973 and 2009 to 2011 by $36 \%$.

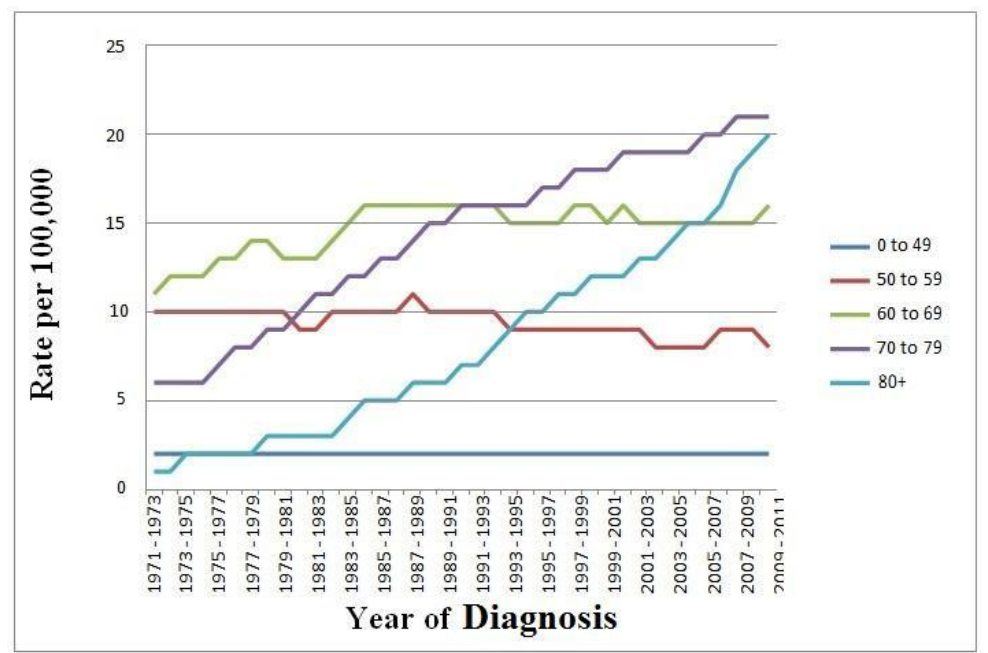

Figure, 4.4: Malignant Brain, Other CNS and Intracranial Tumours (C70-C72, C75.1-C75.3), European Age Standardised Mortality Rates, By Age, Persons, UK, 1971-2011

\section{References}

[1]. Pelvig, DP; Pakkenberg, H; Stark, AK; Pakkenberg, B (2008). "Neocortical glial cell numbers in human brains". Neurobiology of Aging 29 (11): 1754-1762.

[2]. Parent, A; Carpenter MB (1995). "Ch. 1". Carpenter's Human Neuroanatomy. Williams \& Wilkins. ISBN 978-0-683-06752-1.

[3]. Cosgrove, KP; Mazure CM, Staley JK (2007). "Evolving knowledge of sex differences in brainstructure, function, and chemistry". Biol Psychiat 62 (8): 847-55.

[4]. C. Davison Ankney (1992). "Sex differences in relative brain size: The mismeasure of woman,too?". Intelligence 16 (3-4): 329336. doن:10.1016/0160-2896(92)90013-H

[5]. Gur RC, Turetsky BI, Matsui M, Yan M, Bilker W, Hughett P, Gur RE (1999). "Sex differences in brain gray and white matter in healthy young adults: correlations with cognitiveperformance". The Journal of Neuroscience 19 (10): 4065-72. PMID 10234034

[6]. Kandel, ER; Schwartz JH, Jessel TM (2000). Principles of Neural Science. McGraw-HillProfessional. p. 324. ISBN 978-0-83857701-1.

[7]. $\quad$ "How many different types of cancer are there? : Cancer Research UK : CancerHelp UK". Retrieved 11 May 2012.

[8]. Anand P, Kunnumakkara AB, Kunnumakara AB, Sundaram C, Harikumar KB, Tharakan ST, Lai OS, Sung B, Aggarwal BB (September 2008). "Cancer is a preventable disease that requires major lifestyle changes". Pharm. Res. 25 (9): 2097-116. doi:10.1007/s11095-008-9661-9. PMC 2515569. PMID 18626751 
[9]. Kinzler, Kenneth W.; Vogelstein, Bert (2002). "Introduction". The genetic basis of humancancer (2nd, illustrated, revised ed.). New York: McGraw-Hill, Medical Pub. Division. p. 5. ISBN 978-0-07-137050-9.

[10]. Jemal A, Bray, F, Center, MM, Ferlay, J, Ward, E, Forman, D (February 2011). "Globalcancer statistics". CA: a cancer journal for clinicians 61 (2): 69-90. dei:10.3322/caac.20107.PMID 21296855

[11]. National Cancer institute Research on Childhood Cancer, January 2003, http://www.cancer.gov/newscenter/ childhoodcancers.

[12]. McBride ML. 1998. Childhood cancer and environmental contaminants. Canadian Journal of Public Health 89: S53-S62 Suppl 1.

[13]. Sklar C. 2002. Childhood brain tumors. Journal of Pediatric Endocrinology \& Metabolism 15:669-673 Suppl 2.

[14]. Bunin G. 2000. What causes childhood brain tumors? Limited knowledge, many clues. Pediatric Neurosurgery 32:321-326.

[15]. Schottenfeld D. and Fraumeni JF.: Cancer Epidemiology and Prevention, 2nd Edition, OxfordUniversity Press 1996.

[16]. American Cancer Society. 1999a. Brain and Spinal Cord Cancers of Adults. Available at: http://www3.cancer.org/cancerinfo/.

[17]. American Cancer Society. 2001. Cancer Facts \& Figures 2001. Atlanta: American Cancer Society, Inc.

[18]. Preston-Martin and Mack, 1996

[19]. "What you need to know about brain tumors". National Cancer Institute. Retrieved 25 February 2012.

[20]. Ryan T. Merrel, ["Brain Tumours"], "Disease-a-Month" December 2012

[21]. Park, Bong Jin; Kim, Han Kyu; Sade, Burak; Lee, Joung H. (2009). "Epidemiology". In Lee, Joung H. Meningiomas: Diagnosis, Treatment, and Outcome. Springer. p. 11. ISBN 978-1- 84882-910-7.

[22]. "basic facts about glioma". Pediatric brain tumor foundation

[23]. Mamelak AN, Jacoby DB (March 2007). "Targeted delivery of antitumoral therapy to gliomaand other malignancies with synthetic chlorotoxin (TM-601)". Expert Opin Drug Deliv 4 (2):175-86. doi:10.1517/17425247.4.2.175. PMID 17335414.

[24]. Goodenberger ML, Jenkins RB (2012). "Genetics of adult glioma". Cancer Genet.doi:10.1016/j.cancergen.2012.10.009

[25]. Kleihues P, Louis DN, Scheithauer BW, Rorke LB, Reifenberger G, Burger PC, CaveneeWK(2002) The WHO classification of tumors of the nervous system. J Neuropathol Exp Neurol61:215-225 26.

[26]. Reardon DA, Wen PY (2006) Therapeutic advances in the treatment of glioblastoma: rationale and potential role of targeted agents. Oncologist 11:152-164

[27]. Maher EA, Furnari FB, Bachoo RM, Rowitch DH, Louis DN, Cavenee WK, DePinho RA (2001) Malignant glioma: genetics and biology of a grave matter. Genes Dev 15:1311-1333

[28]. Lonardi S, Tosoni A, Brandes AA (2005) Adjuvant chemotherapy in the treatment of high grade gliomas. Cancer Treat Rev 31:7989

[29]. Louis DN, Ohgaki H, Wiestler OD, Cavenee WK (2007) WHO Classification of Tumours of the Central Nervous System. International Agency for Research on Cancer (IARC), Lyon

[30]. Tihan T, Zhou T, Holmes E, Burger PC, Ozuysal S, Rushing EJ (2008) The prognostic value of histological grading of posterior fossa ependymomas in children: a Children's Oncology Group study and a review of prognostic factors. Mod Pathol 21:165-177

[31]. Zamecnik J, Snuderl M, Eckschlager T, Chanova M, Hladikova M, Tichy M, Kodet R (2003) Pediatric intracranial ependymomas: prognostic relevance of histological, immunohistochemical, and flow cytometric factors. Mod Pathol 16:980-991

[32]. Fassett DR, Pingree J, Kestle JR (2005) The high incidence of tumor dissemination in myxopapillary ependymoma in pediatric patients. Report of five cases and review of the literature. J Neurosurg 102:59-64

[33]. Lellouch-Tubiana A, Boddaert N, Bourgeois M, Fohlen M, Jouvet A, Delalande O, Seidenwurm D, Brunelle F, Sainte-Rose C (2005) Angiocentric neuroepithelial tumor (ANET): a new epilepsyrelated clinicopathological entity with distinctive MRI. Brain Pathol 15:281-286

[34]. Wang M, Tihan T, Rojiani AM, Bodhireddy SR, Prayson RA, Iacuone JJ, Alles AJ, Donahue DJ, Hessler RB, Kim JH, Haas M, Rosenblum MK, Burger PC (2005) Monomorphous angiocentric glioma: a distinctive epileptogenic neoplasm with features of infiltrating astrocytoma and ependymoma. J Neuropathol Exp Neurol 64:875-881 35.

[35]. Port JD, Brat DJ, Burger PC, Pomper MG (2002) Astroblastoma: radiologic-pathologic correlation and distinction from ependymoma. AJNR Am J Neuroradiol 23:243-247

[36]. Komori T, Scheithauer BW, Anthony DC, Rosenblum MK, McLendon RE, Scott RM, Okazaki H, Kobayashi M (1998) Papillary glioneuronal tumor: a new variant of mixed neuronalglial neoplasm. Am J Surg Pathol 22:1171-1183

[37]. Ishizawa K, Komori T, Shimada S, Hirose T (2008) Olig2 and CD99 are useful negative markers for the diagnosis of brain tumors. Clin Neuropathol 27:118-128

[38]. Jouvet A, Fauchon F, Liberski P, Saint-Pierre G, Didier-Bazes M, Heitzmann A, Delisle MB, Biassette HA, Vincent S, Mikol J, Streichenberger N, Ahboucha S, Brisson C, Belin MF, Fevre- Montange M (2003) Papillary tumor of the pineal region. Am J Surg Pathol 27:505-512

[39]. Cancer council Australia/clinical oncological society of Australia (2011), ISBN978-09807421-3-8

[40]. Whittle, IR.; Smith, C.; Navoo, P. \& Collie, D. (2004). Meningiomas. Lancet, 363, 9420,1535- 1543, ISSN 0140-6736.

[41]. Seifert, V. (2010). Clinical management of petroclival meningiomas and the eternal quest for preservation of quality of life. Acta Neurochir, 152; 7, pp. 1099-1116, ISSN 0001-6268.

[42]. Yasargil, G. (1980). Meningiomas of the basal posterior cranial fossa. Adv Tech StandNeurosurg, 7, pp. 1-115, ISSN 0095-4829.

[43]. Louis, DN.; Ohgaki, H.; Wiestler, OD.; Cavenee, WK.; Burger, PC.; Jouvet, A.; Scheithauer, BW. \& Kleihues, P. (2007), The 2007 WHO classification of tumours of the central nervous system. Acta Neuropathol, 114, 5, pp. 97-109, ISSN 0001-6322.

[44]. Chohan, MO.; Rehman, T.; Medina-Flores, R.; Clericuzio, C.; Heideman, R. \& Marchand, E. (2011), 16 month-old female with intraventricular mass. Brain Pathol, 21, 3, pp. 349- 50, ISSN 1015-6305.

[45]. Wiemels, J.; Wrensch, M. \& Claus, EB. (2010). Epidemiology and etiology of meningioma. J Neurooncol, 99, 3, pp. 307-314, ISSN $0167-594 X$

[46]. Condra KS; Buatti JM; Mendenhall WM; Friedmann, WA.; Marcus, RB. \& Rhoton, AL. (1997). Benign meningiomas: primary treatment selection affects survival. Int J Radiat Oncol Biol Physiol, 7, 39, pp. 427-436, ISSN 0360-3016.

[47]. Honig, S.; Trantakis, C.; Frerich, B.; Sterker, I.; Kortmann, RD. \& Meixensberger, J. (2010). Meningiomas involving the sphenoid wing outcome after microsurgical treatment-a clinical review of 73 cases. Cen Eur Neurosurg, 71, 4, pp. 189-98, ISSN 18684912.

[48]. Bernhard R. Fischer and Benjamin Brokinkel Department of Neurosurgery, University Hospital of Münster Germany”'Surgical Management of Skull Base Meningiomas - An Overview"

[49]. Bikmaz, K.; Mrak, R. \& Al-Mefty, O. (2007). Management of bone-invasive, hyperostotic sphenoid wing meningioma. J. Neurosurg, 107, 5, pp. 905-912, ISSN 0022-3085.

[50]. Lafferty AR, Chrousos GP: Pituitary tumors in children and adolescents. J Clin Endocrinol Metab 84: 4317-4323, 1999

[51]. Melmed S: Pathogenesis of pituitary tumors. Endocrinol Metab Clin North Am 28: 1-12, 1999

[52]. Kovacs K, Horvath E: Tumors of the pituitary gland. Atlas of tumor pathology 2nd series. Fascicle 21 Armed Forces Institute of Pathology, Washington DC, 1986, pp 1-269

[53]. Missale C, Spano PF: Growth factors in the pathogenesis of prolactin-secreting tumors. J Endocrinol Invest 21: 402-411, 1998

[54]. Surgical Management of Skull Base Meningiomas - An Overview Bernhard R. Fischer and Benjamin Brokinkel Department of Neurosurgery, University Hospital of Münster Germany 
[55]. Hruban RH, Shiu MH, Senie RT, Woodruff JM: Malignant peripheral nerve sheath tumors of the buttock and lower extremity A study of 43 cases. Cancer 1990, 66:1253-1265.

[56]. Angelov L, Guha A: Peripheral Nerve Tumors. In Neuro oncology Essentials 1st edition. Edited by: Berstein M, Berger MS. New York Theme Publishers; 2000:434-444.

[57]. Wanebo JE, Malik JM, VandenBerg SR, Wanebo JH, Driesen N, Persing JA: Malignant peripheral nerve sheath tumors. A clinicopathologic study of 28 cases. Cancer 1993, 71:1247-1253.

[58]. Dasgupta TK, Choudhuri PK: Tumors of soft tissue 2nd edition. Connecticut Appleton \& Lange; 1998:127-395.

[59]. Ducatman SB, Bernd WS, David GP, Herbert MR, Duane MI: Malignant peripheral nerve sheath tumors. A clinicopathologic study of 120 cases. Cancer 1986, 57:2006-2021.

[60]. D'Agostino AN, Soule EH, Miller RH: Sarcoma of the peripheral nerves \& somatic soft tissues associated with multiple neurofibromatosis (Von Recklinghausen's disease). Cancer

[61]. 1963, 16:1015-1027. 61. Stout AP: Tumors of peripheral nervous system: Atlas of tumor pathology, Sect. 2, fasc. 6 Washington, D.C, Armed forces Institute of pathology; 1949.

[62]. 62. Brasfield RD, Das Gupta TK: Von Recklinghausen's disease: A clinicopathological study.

[63]. Ann Surgery 1972, 175:86-104.

[64]. 63. Evans DG, Baser ME, McGaughran J, Sharif S, Howard E, Moran A: Malignant peripheral nerve sheath tumors in neurofibromatosis 1. J Med Genet 2002, 39:311-314.

[65]. 64. Nambisan RN, Rao U, Moore R, Karakousis CP: Malignant soft tissue tumors of nerve sheath origin. J Surg Oncol 1984, 25:268-272.

[66]. 65. Ferner RE, Gutmann DH: International consensus statement on malignant peripheral nerve sheath tumors in neurofibromatosis. Cancer Res 2002, 62:1573-1577

[67]. 66. Bilge B, Ates LE, Demiryont M, Ozger H, Dizdar Y: Malignant peripheral nerve sheath tumors associated with neurofibromatosis Type 1. Pathol Oncol Res 2003, 9:201-205. 67. Suh JS, Abenoza P, Galloway HR, Everson LI, Griffiths HJ: Peripheral (extra cranial) nerve tumors: Correlation of MR imaging and histological findings. Radiology 1992, 183:341-346.

[68]. Parkin, D.M., Whelan, S.L., Feraly, J., Teppo, L., Thomas, D.B. (2002) Cancer Incidence in Five Continents. Vol VIII, IARC Press, Lyon, France.

[69]. Feraly, J., Bray, F., Pisani, P., Parkin, D.M. (2000) Globocan 2000: Cancer Incidence, Mortality and Prevalence Worldwide. IARC Press, Lyon, France.

[70]. Ohgaki, H., Dessen, P., Jourde, B., Horstmann, S., Nishikawa, T., Di Patre, P. L., Burkhard, C., Schuler, D., Probst-Hensch, N. M., Maiorka, P. C., Baeza, N., Pisani, P., Yonekawa, Y., Yasargil, M. G., Lutolf, U. M., and Kleihues, P. (2004) Genetic pathways to glioblastoma: a population-based study. Cancer Res. 64, $6892-6899$

[71]. Burkhard, C., Di Patre, P. L., Sch ü ler, D., Yasargil, M. G., L ü tolf, U., Kleihues, P., and Ohgaki, H. (2003) A populationbased study on the incidence and survival of patients with pilocytic astrocytoma. J Neurosurg. 98, 1170 - 1174

[72]. Claus, E. B. and Black, P. M. (2006) Survival rates and patterns of care for patients diagnosed with supratentorial low-grade gliomas: data from the SEER program, 1973 - 2001. Cancer. 106, 1358 - 1363.

[73]. Tseng, J. H., Merchant, E., and Tseng, M. Y. (2006) Effects of socioeconomic and geographic variations on survival for adult glioma in England and Wales. Surg. Neurol. 66, $258-263$.

[74]. Tseng, M. Y. and Tseng, J. H. (2005) Survival analysis for adult glioma in England and Wales. J. Formos Med. Assoc. 104, 341 348.

[75]. Oertel, J., von Buttlar, E., Schroeder, H. W., and Gaab, M. R. (2005) Prognosis of gliomas in the 1970s and today. Neurosurg. Focus. 18, e12

[76]. McKean-Cowdin, R., Preston-Martin, S., Pogoda, J. M., Holly, E. A., Mueller, B. A., and Davis, R. L. (1998) Parental occupation and childhood brain tumors: astroglial and primitive neuroectodermal tumors. J. Occup. Environ. Med. 40, $332-340$.

[77]. Data were provided by the Office for National Statistics on request, March 2013. Similar data can be found here: http:// www.ons.gov.uk/ons/publications/all- releases.html?definition=tcm\%3A77-27475.

[78]. Data were provided by ISD Scotland on request, November 2012. Similar data can be found here: http://gro-scotland.gov.uk/ statistics/theme/vital-events/general/ref-tables/index.html.

[79]. Data were provided by the Northern Ireland Cancer Registry on request, May 2013. Similar data can be found here: http:// www.nisra.gov.uk/demography/default.asp22.htm. 